\title{
Constraints Faced by the Pineapple Crop Growers at Various Levels of Farms in Selected Districts of Nagaland and Manipur States
}

\author{
Th. Motilal Singh and Amod Sharma* \\ Department of Agricultural Economics, School of Agricultural Sciences and Rural \\ Development, Nagaland University, Medziphema Campus, Nagaland-797106, India \\ *Corresponding author
}

\begin{abstract}
A B S T R A C T
Keywords

Nagaland, Manipur, Pineapple, Growers, Levels, Constraints

Article Info

Accepted:

22 June 2020

Available Online:

10 July 2020

In India, agriculture is important occupation of which 52.00 per cent of the people depend for their livelihood. Although agriculture dominates the primary sector however it has not reached its potential level, since most of the farmers use traditional technology, slow adoption of modern and proven technologies which impaired productivity and results in lower standard living of the framers in the region. The proposed study comprises both primary and secondary data have been collected. The primary relevant information of the proposed study has been collected by adopting personal interview method from the selected farm households in the study area for agricultural year 2016 to 2018. The present study identified the major production and marketing constraints faced by the horticultural growers in the different location of the Nagaland and Manipur both the states across the categories.
\end{abstract}

\section{Introduction}

Village-Community System of farming exists in different parts of the world becomes an indispensable part if the concept of sustainability arises. Different Taboos or culture and practices have been maintain in certain agricultural heritage site of the world and this heritage becomes the basis for their social, economic life since time immoral (Small Holders farming Mechanism).

Back to our nation, India's agricultural scenario was also facing the problems of population growth, post Independence political dilemma across the union of India and the great Famine during the two decades had led to the rise of Green Revolution in the 60s. With these, agricultural modernization emerged and the India's food grains production figure became almost the doubled. Agriculture infrastructural development had given priorities during the India's Five Years Plan and resulted in a positive impact on the production scenario of the nation till she witnessed an irregular and sharp declined in the production and productivity level of some major food crops. Eminent Scientists, Experts, Policy makers \& Planners and different Stakeholders reveals that the country un-sustainability like scenario in the entire agricultural system may be attributed by 
many factors such as injudicious use of synthetic inorganic inputs in the production processes, deterioration of natural resources and society-triggered climate change phenomena.

It is also estimated that the India's population will reach 1.2 billion by 2030 . Again with the advancement of Health Sciences, Indian consumers are realizing on the healthy food for the future perspectives. The present Government of India also emphasizes on the Doubling of Farm Income through various technologies intervention on sustainable approach by 2022 . Bringing or balancing the entire scenario on the sustainable basis requires integrated and cumulative efforts of different Stakeholders from Top to Bottom or Bottom to Top approach through indebt study and understanding of the present existing systems and their nature of resource management patterns.

Again focusing on the North Eastern India, the total agricultural scenario is quite peculiar and can be differentiated from the agricultural system of Northern, Central and Southern India's agricultural practices or patterns. The entire region comprises of seven hilly states vizely Arunachal Pradesh, Manipur, Meghalaya, Mizoram, Nagaland, Sikkim and Tripura.

\section{Materials and Methods}

The present study has been carried out in Manipur and Nagaland both state in consultation with the organizations and the line-departments working in the field of Organic farming at the first and secondly the feasibility of the researcher. A multi-stagerandom sampling technique has been used for the selection of sample units. Both purposive and cluster sampling method have been used for the selection districts, blocks and surveyed of the sample sizes.
In the first stage of sampling, selection of district has been carried out. Dimapur and Kohima districts from Nagaland and Senapati and Thoubal districts from Manipur were selected purposively for the study because of its popularity and production of major horticultural crops in the District.

In the second stage of sampling, block having highest acreage and production of major horticultural crops under the selected district have been selected with the help of District Agriculture Department and other reputed institutes. Kohima and Medziphema from Nagaland and Thoubal \& Mao-Maram blocks from Manipur were purposively selected to get the desire information on the above objectives.

In the third stage of sampling plan, a list of villages under the selected block was prepared with the help of Block Development Officer / District Agriculture Department and ICAR institutes. From the villages available in this concerned district, villages which have popularity and production of major horticultural crops were randomly selected for further selection of respondent farmers by using simple random sampling without replacement. Accordingly, Medziphema and Jakhama from Nagaland and Phikomai; Kalinamei and Waithou Chiru were selected for the study.

In the fourth stage of sampling plan, with the help of the selected villages, authority (Headman) and KVKs institutes, the farmers who cultivate pineapple and potato were analysed and from these villages, 300 farmers (150 respondent farmers from Manipur and 150 respondent farmers from Nagaland) were selected for each crop (i.e 75 farmers/ crop) for the data collection of the above crops. From the prepared farmers list, by adopting stratified random sampling, proportional allocation and cluster sampling techniques, 
the respondent farmers were drawn for collection of information using pre-tested schedule.

The categorizations of household farmers into marginal, small and medium group were done on the basis of their operational land holdings as follows:

$\begin{array}{ll}\text { Marginal } & : \text { Less than ha } \\ \text { Small } & : 1.01 \text { to } 2 \text { ha } \\ \text { Medium } & : 2.01 \& \text { above. }\end{array}$

A complete list of farmers along with their holding size was prepared from each of the selected villages with the help of village headman / Chairman / pradhan of the respective villages. While preparing the list due consideration was given to those farmers who have devoted at least twenty percent of their net sown area to the particular selected vegetables for inclusion in the final list of the selected household. In the third stage farmers was selected randomly each from a selected village to get optimum sample size. Finally, the farmer respondents were classified into different categories or marginal, small and medium size groups.

To determine the optimum sample size two step approaches was be used, first a preliminary sample size was selected using simple random sampling without replacement (SRSWOR) to estimate the population parameter values, which in turn was used to determine the final sample size. Secondly, the preliminary sample was augmented by drawing additional units from the population so that the size of the augmented sample is same as the required sample size (Ravindra and Nauran 1975).

Let $n 1$ be the size of preliminary sample selected using simple random sampling without replacement (SRSWOR) then sample mean square.

$$
\begin{aligned}
& \mathrm{S}_{1}{ }^{2}=\begin{array}{l}
\mathrm{n}_{1} \\
\mathrm{n}_{1}-1
\end{array} \\
& \quad-------\sum \mathrm{i}=1\left(\mathrm{y}_{\mathrm{i}}-\mathrm{y}_{1}\right)^{2}
\end{aligned}
$$

Table 9. $\mathrm{n}_{1}$

Where, $y=$--------- $-\sum_{i=1}$ is the preliminary sample mean.

$\mathrm{N}_{1}$

Sample size required for estimating population mean with permissible error B is given by;

$$
\mathrm{n}=\frac{\mathrm{N}_{\mathrm{S} 1}^{2}}{\mathrm{ND}+\mathrm{s}^{2}}{ }^{2}
$$

Where, $\mathrm{D}=$ = ------------ and $\mathrm{N}=$ size of the population i.e., total number of vegetable

$$
4
$$

Growing farmers.

\section{Results and Discussion}

The major production constraints faced by the horticultural growers in the different location of the state across the categories were recommended that documentation of the activities encouraged during the adoption of farm activities and further to increase the farm efficiency. There are many major constraints depends upon the location and crops selected during the years, however the major horticultural growers during study period time for the production related issues are of six (6) are types as major sub-constraints viz; seed related, labour related, irrigation related, manure and fertilizer related and plant protection measures related and other related constraints / issues.

Table 1 reveals the constraints faced by the respondent farmers in the production of the selected crops have been calculated and ranked using Garette ranking technique or 
conventional technique. Possible solutions of the problems will be identified to enhance productivity of the crops by the respondent farmers. The major constraints faced during the production of the major horticultural crop growers in the Nagaland state, it was seed related issues with highest for low reliability with 67.00 per cent growers and it was found to be lowest with 39.00 per cent for price are high. Even for the labour related issues maximum was found with 56.00 per cent on skilled labour are not available in time and it was found to be minimum with 44.00 per cent for high wage rates. For irrigation related issues it was found to be maximum with 53.00 per cent for the irrigation facility not reliable and minimum 45.00 per cent it was for the irrigation facility not available. While for the manure and fertilizer related issues it was found to be maximum for the inorganic fertilizers are not suitable with 70.00 per cent and it was found to be minimum with 41.00 per cent with high transportation costs. Whereas the plant protection measures related issues was found to be maximum with 63.00 per cent, are facing due to lack of knowledge about chemicals and it was found to be minimum with 39.00 per cent were in the opinion it was due to the high prices. Further other related constraints faced was the growers was found to be maximum of pest and disease related issues with 72.00 per cent and it was minimum is due to the weeds related problems with 31.00 per cent, respectively. The similar study and recommendation has been suggested by the Sharma et al., (2000); Jamir and Sharma (2012); Sharma (2014); Vengoto and Sharma (2018); Yadav and Sharma (2019) for achieving the desired objectives and augments in the support of the farmer's production efficiency in the region.

Table 2 reveals that the major constraints faced during the production of the major horticultural crop growers in the Manipur state, it was seed related issues, it was found to be highest for low reliability with 61.00 per cent growers and it was found to be lowest with 38.00 per cent for price are high. Even for the labour related issues maximum was found with 53.00 per cent on skilled labour are not available in time and it was found to be minimum with 42.00 per cent for high wage rates. For irrigation related issues it was found to be maximum with 54.00 per cent for the irrigation facility not reliable and minimum 46.00 per cent it was for the irrigation facility not available. While for the manure and fertilizer related issues it was found to be maximum for the inorganic fertilizers are not suitable with 66.00 per cent and it was found to be minimum with 41.00 per cent with high transportation costs. Whereas the plant protection measures related issues was found to be maximum with 75.00 per cent, are facing due to lack of knowledge about chemicals and it was found to be minimum with 24.00 per cent were in the opinion it was due to the high prices. Further other related constraints faced was the growers was found to be maximum of pest and disease related issues with 72.00 per cent and it was minimum is due to the weeds related problems with 47.00 per cent, respectively. The similar study and recommendation has been suggested by the Sharma and Singh (2001); Sharma (2011); Kent and Sharma (2014); Choudhary et al., (2017); Sharma et al, (2018); Kulshrestha et al., (2020) for achieving the desired objectives and augments in the support of the farmer's production efficiency in the region.

The major marketing constraints faced by the horticultural growers in the different location of the state across the categories were recommended that documentation of the activities encouraged during the adoption of farm activities and further to increase the farm efficiency. There are many major constraints depends upon the location, types of markets 
and crops deals / selected during the agricultural year, however the major horticultural growers faced during study period time for the marketing related issues are of seven (7) types as major sub-constraints viz; grading related, packaging related, transportation related, weighting related, marketing information related and other related constraints / issues.

Table.1 Production problems faced by the pineapple growers in Nagaland $(\mathrm{n}=150)$

\begin{tabular}{|c|c|c|c|c|}
\hline Sl. No & Problem/ Constraints & Total Score & Average Score & $\begin{array}{l}\text { Garrett } \\
\text { ranking }\end{array}$ \\
\hline 1 & \multicolumn{4}{|l|}{ Seed related } \\
\hline a. & Low reliability & 925 & 67.00 & I \\
\hline b. & Quality of the seed not good & 2775 & 47.00 & II \\
\hline c. & Not Available in time & 2825 & 46.00 & III \\
\hline d. & Price are high & 3475 & 39.00 & IV \\
\hline 2. & \multicolumn{4}{|l|}{ Labour related } \\
\hline a. & Skilled labour not available in time & 1833.33 & 56.00 & I \\
\hline b. & $\begin{array}{l}\text { Unskilled labour not available in } \\
\text { time }\end{array}$ & 2633.33 & 48.00 & II \\
\hline c. & High wage rates & 3033.33 & 44.00 & III \\
\hline 3. & \multicolumn{4}{|l|}{ Irrigation related } \\
\hline a. & Irrigation facility not reliable & 2166.67 & 53.00 & I \\
\hline b. & Perennial sources are not available & 2366.67 & 51.00 & II \\
\hline c. & Irrigation facility not available & 2966.67 & 45.00 & III \\
\hline 4. & \multicolumn{4}{|l|}{ Manures \& Fertilizers related } \\
\hline $\mathbf{a}$ & Inorganic fertilizers are not suitable & 740.00 & 70.00 & I \\
\hline b & Desired brand not available & 2220.00 & 52.00 & II \\
\hline c & Not available at proper time & 3060.00 & 44.00 & III \\
\hline d & High prices of organic sources & 3160.00 & 43.00 & IV \\
\hline e & High transportation costs & 3320.00 & 41.00 & $\mathrm{~V}$ \\
\hline 5. & \multicolumn{4}{|l|}{ PPCs related } \\
\hline a & $\begin{array}{l}\text { Lack of knowledge about } \\
\text { chemicals }\end{array}$ & 1200.00 & 63.00 & I \\
\hline b & Desired brand not available & 2040.00 & 54.00 & II \\
\hline c & $\begin{array}{l}\text { Don't know proper method of } \\
\text { spraying }\end{array}$ & 2380.00 & 51.00 & III \\
\hline d & $\begin{array}{l}\text { Don't know proper dose, time of } \\
\text { application }\end{array}$ & 3400.00 & 40.00 & IV \\
\hline e & High price & 3480.00 & 39.00 & V \\
\hline 6. & \multicolumn{4}{|l|}{ Other related constraints } \\
\hline $\mathbf{a}$ & Pests \& Diseases & 625.00 & 72.00 & I \\
\hline b & Animals & 2525.00 & 49.00 & II \\
\hline c & Anti social \& ethnic problems & 2750.00 & 47.00 & III \\
\hline d & Weeds & 4100.00 & 31.00 & IV \\
\hline
\end{tabular}


Table.2 Production problems faced by the pineapple growers in manipur $(n=150)$

\begin{tabular}{|l|l|l|l|l|}
\hline SI. No & Problem/ Constraints & Total Score & Average Score & $\begin{array}{l}\text { Garrett } \\
\text { ranking }\end{array}$ \\
\hline $\mathbf{1}$ & Seed related & & \\
\hline a. & Low reliability & 1400 & 61.00 & I \\
\hline b. & Quality of the seed not good & 2450 & 50.00 & II \\
\hline c. & Not Available in time & 2525 & 49.00 & III \\
\hline d. & Price are high & 3625 & 38.00 & IV \\
\hline 2. & Labour related & & & \\
\hline a. & Unskilled labour not available in time & 2100.00 & 53.00 & I \\
\hline b. & Skilled labour not available in time & 2166.67 & 52.00 & II \\
\hline c. & High wage rates & 3233.33 & 42.00 & III \\
\hline 3. & Irrigation related & & & \\
\hline a & Irrigation facility not reliable & 2066.67 & 54.00 & I \\
\hline b & Perennial sources are not available & 2600.00 & 49.00 & II \\
\hline c & Irrigation facility not available & 2833.33 & 46.00 & III \\
\hline 4. & Manures \& Fertilizers related & & & \\
\hline a & Desired brand not available & 1040.00 & 66.00 & I \\
\hline b & Not available at proper time & 2280.00 & 52.00 & II \\
\hline c & Inorganic fertilizers are not suitable & 2820.00 & 46.00 & III \\
\hline d & High transportation costs & 3040.00 & 44.00 & IV \\
\hline e & High prices of organic sources & 3320.00 & 41.00 & V \\
\hline 5. & PPCs related & 2760.00 & 47.00 & IV \\
\hline a & Desired brand not available & 500.00 & 75.00 & I \\
\hline b & Lack of knowledge about chemicals & 1500.00 & 60.00 & II \\
\hline c & Don't know proper method of spraying & 2500.00 & 50.00 & III \\
\hline d & $\begin{array}{l}\text { Don't know proper dose, time of } \\
\text { application }\end{array}$ & 3500.00 & 39.00 & IV \\
\hline e & High price & 4500.00 & 24.00 & V \\
\hline 6. & Other related problems & & & \\
\hline a & Pests \& Diseases & Anti social \& ethnic problems & 72.00 & I \\
\hline b & Animals & Weeds & 53.00 & II \\
\hline c & & & & \\
\hline d & & & & \\
\hline & & & & \\
\hline
\end{tabular}


Table.3 Marketing constraints faced by the pineapple growers in Nagaland $(n=150)$

\begin{tabular}{|c|c|c|c|c|}
\hline Sl. No & Problem / Constraints & Total Score & $\begin{array}{l}\text { Average } \\
\text { Score }\end{array}$ & $\begin{array}{l}\text { Garrett } \\
\text { ranking }\end{array}$ \\
\hline 1 & \multicolumn{4}{|l|}{ Grading related } \\
\hline $\mathbf{a}$ & Hand grading leads to quality deterioration & 625.00 & 73.00 & $\mathrm{I}$ \\
\hline b & Grading standards not specific & 3050.00 & 45.00 & II \\
\hline c & Mechanical grading facilities not available & 3100.00 & 44.00 & III \\
\hline d & Grading by hand is costly & 3225.00 & 42.00 & IV \\
\hline 2. & \multicolumn{4}{|l|}{ Packaging related } \\
\hline $\mathbf{a}$ & Packing materials not available in time & 1900.00 & 56.00 & I \\
\hline $\mathbf{b}$ & Pack of quality packing materials & 2600.00 & 49.00 & II \\
\hline c & $\begin{array}{l}\text { Lack of knowledge regarding packaging and } \\
\text { packing materials }\end{array}$ & 2725.00 & 48.00 & III \\
\hline d & Costly packing materials & 2775.00 & 47.00 & IV \\
\hline 3. & \multicolumn{4}{|l|}{ Transportation related } \\
\hline $\mathbf{a}$ & Lack of all weather/ metallic roads & 780.00 & 70.00 & I \\
\hline b & Unauthorized and illegal taxes & 1500.00 & 60.00 & II \\
\hline c & Lack of linking roads & 3280.00 & 42.00 & III \\
\hline d & $\begin{array}{l}\text { Quick and timely transportation facilities not } \\
\text { available }\end{array}$ & 3420.00 & 41.00 & IV \\
\hline e & High transportation charges & 3520.00 & 40.00 & $\mathrm{~V}$ \\
\hline 4. & \multicolumn{4}{|l|}{ Weighing related } \\
\hline $\mathbf{a}$ & Weighing not done accurately & 2400.00 & 51.00 & I \\
\hline $\mathbf{b}$ & Use of improper scales & 2600.00 & 49.00 & II \\
\hline 5. & \multicolumn{4}{|l|}{ Price related } \\
\hline $\mathbf{a}$ & Low prices & 2200.00 & 53.00 & I \\
\hline $\mathbf{b}$ & No support prices & 2433.33 & 51.00 & II \\
\hline c & Glut in peak marketing season & 2866.67 & 46.00 & III \\
\hline 6. & \multicolumn{4}{|l|}{ Market informations related } \\
\hline $\mathbf{a}$ & $\begin{array}{l}\text { No reliable sources of distant market } \\
\text { informations }\end{array}$ & 2400.00 & 51.00 & I \\
\hline $\mathbf{b}$ & Lack of timely availability of market news & 2600.00 & 49.00 & II \\
\hline 7. & \multicolumn{4}{|l|}{ Other related constraints / issues } \\
\hline $\mathbf{a}$ & Frequent ban \& social boycott & 625.00 & 73.00 & I \\
\hline b & Lack ofcooperations among the producers & 2700.00 & 48.00 & II \\
\hline c & Lack of govt. policies & 3000.00 & 45.00 & III \\
\hline d & Non availability of market shed & 3675.00 & 37.00 & IV \\
\hline
\end{tabular}


Table.4 Marketing constraints face by the pineapple growers in Manipur ( $\mathrm{n}=150)$

\begin{tabular}{|c|c|c|c|c|}
\hline Sl. No & Problem/ Constraints & $\begin{array}{l}\text { Total } \\
\text { Score }\end{array}$ & $\begin{array}{l}\text { Average } \\
\text { Score }\end{array}$ & $\begin{array}{l}\text { Garrett } \\
\text { ranking }\end{array}$ \\
\hline 1. & \multicolumn{4}{|l|}{ Grading related } \\
\hline $\mathbf{a}$ & Hand grading leads to quality deterioration & 925.00 & 68.00 & $\mathrm{I}$ \\
\hline $\mathbf{b}$ & Grading standards not specific & 2550.00 & 49.00 & II \\
\hline c & Grading by hand is costly & 3250.00 & 43.00 & III \\
\hline d & Mechanical grading facilities not available & 3275.00 & 42.00 & IV \\
\hline 2. & \multicolumn{4}{|l|}{ Packaging related } \\
\hline $\mathbf{a}$ & Packing materials not available in time & 1800.00 & 57.00 & I \\
\hline $\mathbf{b}$ & Costly packing materials & 2550.00 & 50.00 & II \\
\hline c & Lack of quality packing materials & 2725.00 & 48.00 & III \\
\hline d & $\begin{array}{l}\text { Lack of knowledge regarding packaging and packing } \\
\text { materials }\end{array}$ & 2925.00 & 46.00 & IV \\
\hline 3. & \multicolumn{4}{|l|}{ Transportation related } \\
\hline $\mathbf{a}$ & Lack of linking roads & 1420.00 & 61.00 & $\mathrm{I}$ \\
\hline b & Quick and timely transportation facilities not available & 1840.00 & 57.00 & II \\
\hline c & Lack of all weather/ metallic roads & 2280.00 & 52.00 & III \\
\hline d & High transportation charges & 3400.00 & 41.00 & IV \\
\hline e & Unauthorized and illegal taxes & 3560.00 & 39.00 & $\mathrm{~V}$ \\
\hline 4. & \multicolumn{4}{|l|}{ Weighing related } \\
\hline $\mathbf{a}$ & Weighing not done accurately & 2050.00 & 54.00 & I \\
\hline b & Use of improper scales & 2950.00 & 46.00 & II \\
\hline 5. & \multicolumn{4}{|l|}{ Price related } \\
\hline $\mathbf{a}$ & Low prices & 2000.00 & 55.00 & I \\
\hline b & No support prices & 2700.00 & 48.00 & II \\
\hline c & Glut in peak marketing season & 2800.00 & 47.00 & III \\
\hline 6. & \multicolumn{4}{|l|}{ Market informations related } \\
\hline $\mathbf{a}$ & Lack of timely availability of market news & 2000.00 & 55.00 & I \\
\hline $\mathbf{b}$ & No reliable sources of distant market informations & 3000.00 & 45.00 & II \\
\hline 7. & \multicolumn{4}{|l|}{ Other related Problems } \\
\hline $\mathbf{a}$ & Frequent ban \& social boycott & 2050.00 & 54.00 & I \\
\hline b & Non availability of market shed & 2300.00 & 52.00 & II \\
\hline c & Lack of cooperations among the producers & 2450.00 & 51.00 & III \\
\hline d & Lack of govt. policies & 3200.00 & 43.00 & IV \\
\hline
\end{tabular}


Fig.1 Schematic representation of sampling plan- i

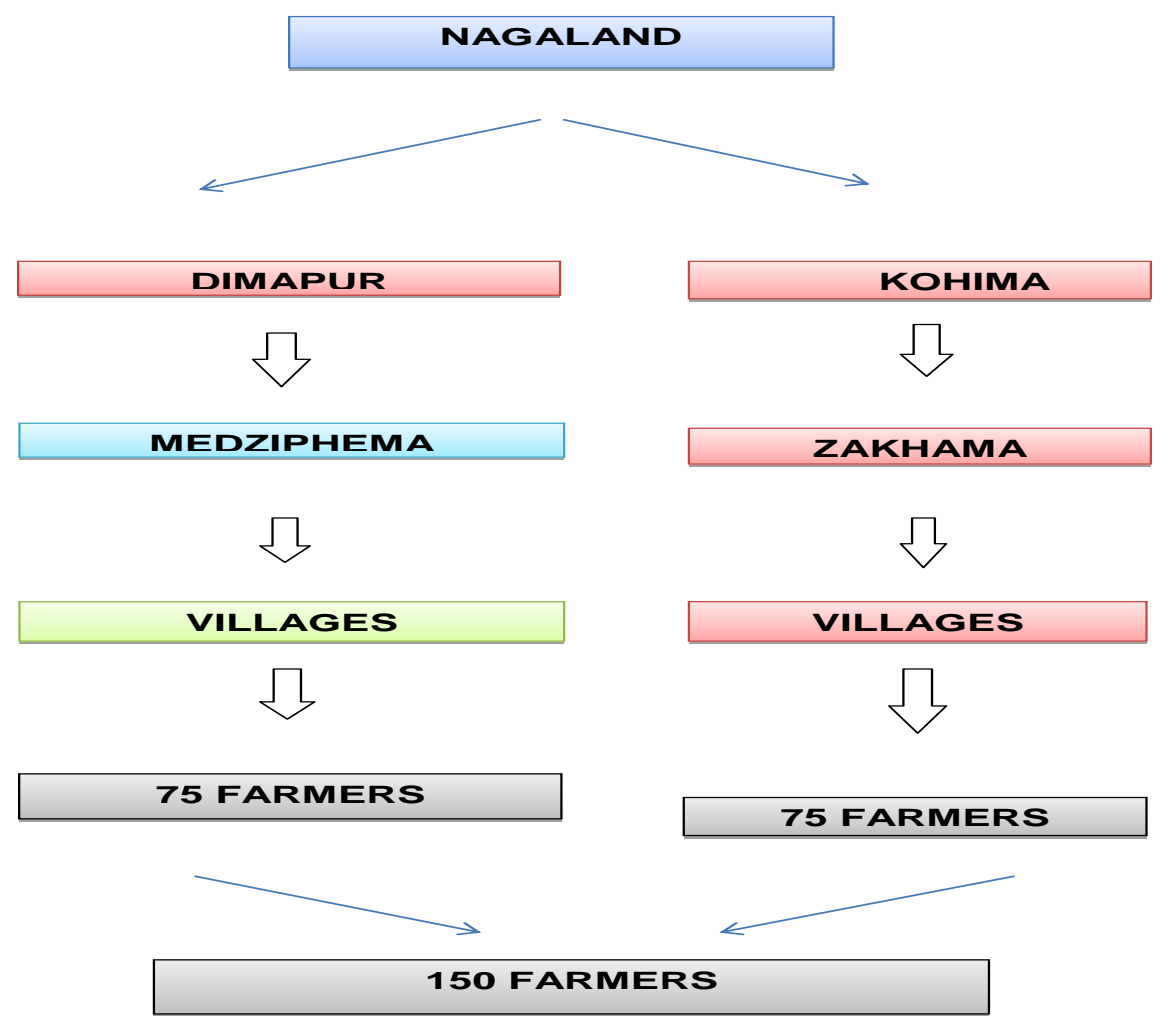

Fig.2 Schematic representation of sampling plan- ii

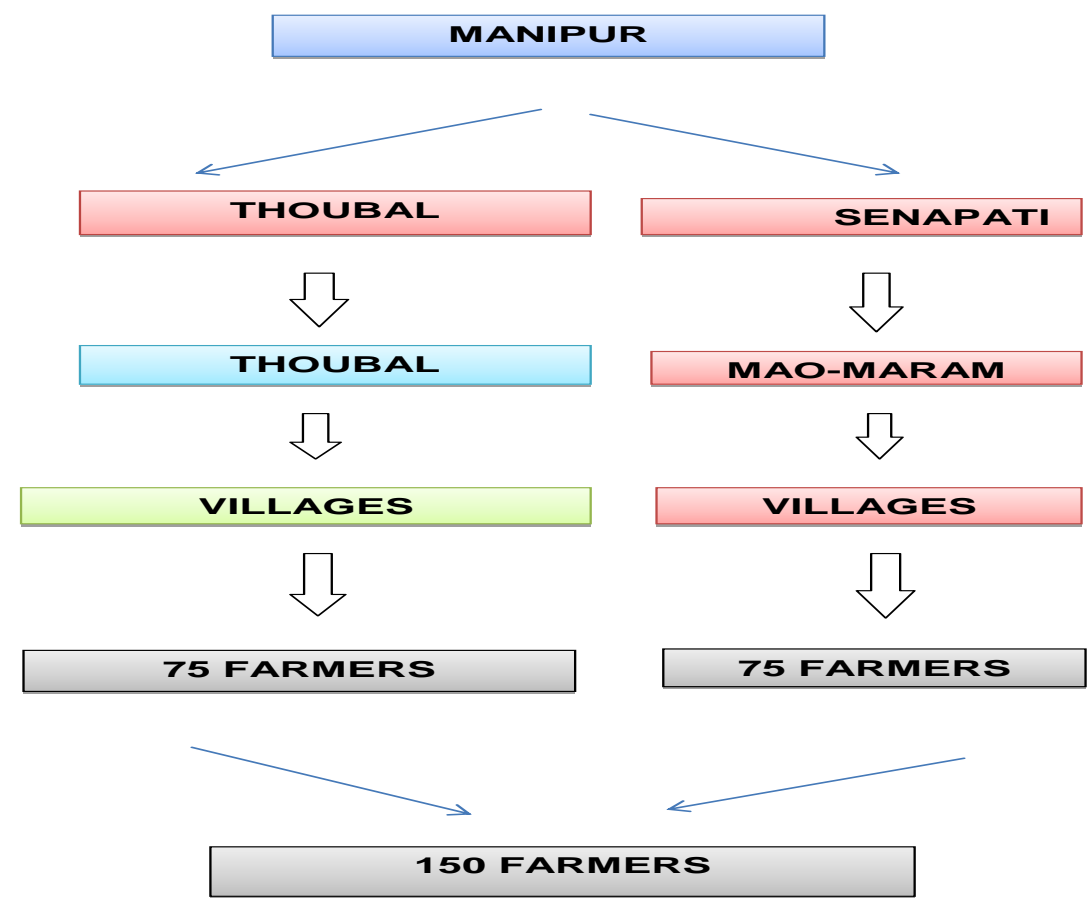


Table 3 reveals that the major constraints faced during the marketing of the major horticultural crop growers in the Nagaland state, it was grading related issues with highest for hand grading leads to quality deterioration with 73.00 per cent of the growers and it was found to be lowest with 42.00 per cent for grading by hand is costly. Also for the packaging related issue maximum was found with 56.00 per cent on packing materials not available in time and it was found to be minimum with 47.00 per cent for costly packing materials. For the transportation related issues the maximum with 70.00 per cent was due to the lack of all weather / metallic roads and it was found to be minimum with 40.00 per cent high transportation charges. Further for the weighting related issue, it was found to be maximum for weighing not done accurately with 51 per cent and it was found to be minimum with 49.00 per cent for the use of improper scales. The sixth constraints faced by the growers is the marketing information related issues, it was found to be maximum with 51.00 per cent for no reliable sources of distant market informations and it was found to be minimum with 49.00 per cent due to the lack of timely availability of market news. Further the other related constraints / issues faced by the growers was found maximum with 73.00 per cent for frequent ban and social boycott and it was found to be minimum with 37.00 per cent for non availability of market shed, respectively. The similar study and recommendation has been suggested by the Sharma (2005); Sharma (2013); Sharma (2014) Das and Sharma (2018); Imlibenla and Sharma (2019) for achieving the desired objectives and augments in the support of the farmer's marketing efficiency to enhance the farm income in the region.

Table 4 reveals that the major constraints faced during the marketing of the major horticultural crop growers in the Manipur state, it was grading related issues with highest for hand grading leads to quality deterioration with 68.00 per cent of the growers and it was found to be lowest with 42.00 per cent for grading by hand is costly. Also for the packaging related issue maximum was found with 57.00 per cent on packing materials not available in time and it was found to be minimum with 46.00 per cent for costly packing materials. For the transportation related issues the maximum with 61.00 per cent was due to the lack of all weather / metallic roads and it was found to be minimum with 39.00 per cent high transportation charges. Further for the weighting related issue, it was found to be maximum for weighing not done accurately with 55 per cent and it was found to be minimum with 47.00 per cent for the use of improper scales. The sixth constraints faced by the growers is the marketing information related issues, it was found to be maximum with 55.00 per cent for no reliable sources of distant market informations and it was found to be minimum with 45.00 per cent due to the lack of timely availability of market news. Further the other related constraints / issues faced by the growers was found maximum with 54.00 per cent for frequent ban and social boycott and it was found to be minimum with 43.00 per cent for non availability of market shed, respectively. The similar study and recommendation has been suggested by the Sharma et al., (2012); Sharma et al, (2016); Singh et al., (2018); Dinesh and Sharma (2019) for achieving the desired objectives and augments in the support of the farmer's marketing efficiency to enhance the farm income in the region.

In conclusion the present study highlights or identified the major production and marketing constraints faced by the horticultural growers in the different location of the Nagaland and Manipur both the states across the categories. 
So the directorate of horticulture, policy makers, extension workers, researchers, nongovernment organization and other marketing functionaries involved actively will be getting the feedback to improve their strategy to improve the production as well as marketing efficiency for betterment of future fair prices etc; both the buyers and sellers in general, so the present study activities encouraged during the adoption of farm activities constraints and further to increase the farm efficiency in the days to come.

\section{References}

Choudhary, Ramjilal.; Rathore, D.S. and Sharma, Amod. 2017. An Economics Analysis of Production and Marketing of Groundnut in Porbandar District of Gujarat. Economic Affairs. 62(3). September: 547-553.

Das, Kandarpa Kumar. and Sharma, Amod. 2018. Effects on Input Use on Rapeseed and Mustard Production in Nagaon district of Assam. International Journal of Current Microbiology and Applied Sciences. 7(5). May: 629-634.

Dinesh, V. and Sharma, Amod. 2019. A Financial Implication Analysis of different Layer Poultry Farms in Nammakkal district. International Journal of Current Microbiology and Applied Sciences. 8(6): 938-946.

Imlibenla and Sharma, Amod. 2019. Farm Efficiency Measure Analysis of Tea Plantation crop in Mokokchung district of Nagaland. International Journal of Current Microbiology and Applied Sciences. 8(6): 1156-1163.

Jamir, Moanukshi. and Sharma, Amod. 2014. A Sustainable Production and Marketing of cucumber crop in the Hilly Zone of Nagaland. Technofame. 3(1). May: 61-66.

Kent, Yuntilo. and Sharma, Amod. 2014. Economic Efficiency on different breeds of Poultry birds under Backyard Management System in Dimapur district of Nagaland. Progressive Agriculture. 14(1): 168-177.

Kulshrestha, R.K. Sharma, V.K. and Sharma, Amod. 2020. A study of Economics of Milk Production in Firozabad district of Western Uttar Pradesh. Plant Achivers. (Accepted for Vol. 20 July 2020).

Sharma, A. and Singh, A.K. 2001. Price Spread of Potato Farmers by Different Farm Size Group in Firozabad District of UP. Andhra Agricultural Journal. 48(1-2): 124-127.

Sharma, A. Chauhan, S. Singh, A.K. Sharma, S.K. and Singh, S.P. 2000. Economics Of Milk Production on Different Farm Size Groups. Dairy Guide. XXI(3-4). July to December: 61-66.

Sharma, Amod. 2005. Economics of Milk Production of Milch Animals on Different Farm Size Groups. The Andhra Agricultural Journal. 52(1-2): 253-257.

Sharma, Amod. 2011. Economic and Constraints of King Chilli Growers in Dimapur District of Nagaland. Journal of Interacademicia. 15(4): 710-719.

Sharma, Amod. 2012. Inter-state Disparities in Socio-economic Development in North East Region of India. Journal of Agricultural Science. 4(9). September: 236-243.

Sharma, Amod. 2013. Economics of Production and Marketing of King Chilli in Dimapur District of Nagaland. Indian Journal of Agricultural Marketing. 27(2). May-Aug: 128-141.

Sharma, Amod. 2014. Sustainable economic analysis and extent of satisfaction level of King Chilli growers in Nagaland. Agriculture for Sustainable Development. 2(1). June: 188-191.

Sharma, Amod.; Kichu, Yimkumba. and Chaturvedi, B.K. 2016. Economics and Constraints of Pineapple Cultivation in 
Dimapur District of Nagaland. The Journal of Rural and Agricultural Research. 16(1). January: 72-75.

Sharma, Amod.; Kichu, Yimkumba. and Sharma, Pradeep. Kumar. 2018. Sustainable economic analysis and constraints faced by the pineapple growers in Nagaland. Progressive Agriculture. 18(1). February: 27-33.

Sharma, Amod.; Singh, J.; Hussain, M.; Tyagi, D.B. and Singh, N.P. 2012. Economics of Saffron (Kesar) Cultivation in Jammu and Kashmir. Environment and Ecology. 30(3C). September: 1070-1075.

Singh, Jaspal. Sharma, Amod., Tyagi, D.B. and Singh, S.P. 2018. Impact of SocioEconomic Variables on the Knowledge and Adoption of the Diversified
Agriculture Technologies - A Case Study of DASP adopted villages of Sasni block of Hathras District (UP). International Journal of Current Microbiology and Applied Sciences. 7(5). May: 3095-3102.

Vengoto, Venyo. and Sharma, Amod. 2018. Economic and Constraint of Potato crop in Kohima district of Nagaland. Technoframe. 7(1):75-80.

Yadav, Mukesh. Kumar. and Sharma, Amod. 2019. Effects of socio-economic and occupation on beneficiary and nonbeneficiary Water-shed management catchment areas in the state of Nagaland. International Journal of Current Microbiology and Applied Sciences. 8(9): 1566-1575.

\section{How to cite this article:}

Motilal Singh, Th. and Amod Sharma. 2020. Constraints Faced by the Pineapple Crop Growers at Various Levels of Farms in Selected Districts of Nagaland and Manipur States. Int.J.Curr.Microbiol.App.Sci. 9(07): 2684-2695. doi: https://doi.org/10.20546/ijcmas.2020.907.316 